\title{
Intenção comportamental de agricultores do Oeste de Santa Catarina para a conservação de florestas nativas
}

\author{
Elaine Zuchiwschi \\ Fundação do Meio Ambiente de Santa Catarina \\ Alfredo Celso Fantini \\ Universidade Federal de Santa Catarina
}

\begin{abstract}
Resumo
Conciliar a conservação de florestas nativas e a produção agropecuária em estabelecimentos rurais é uma tarefa complexa que demanda abordagens sistêmicas e multidisciplinares que incluam, além de aspectos biológicos dos recursos, outros de natureza socioeconômica, cultural e mesmo psicológica. Para identificar e comparar a intenção comportamental de agricultores da região Oeste de Santa Catarina para a conservação e manejo de florestas nativas em seus imóveis rurais, foi utilizada neste trabalho a Teoria do Comportamento Planejado. Verificou-se que a Intenção Comportamental de agricultores de diferentes sistemas de produção e de agricultores com e sem dependência por recursos florestais nativos para compor a renda, diferem. Diferenças entre grupos de agricultores em relação aos resultados da Atitude e do Controle Comportamental Percebido estavam associadas de forma coerente com aspectos socioeconômicos e ambientais. Os resultados das Normas Subjetivas indicam que a família é a principal referência dos agricultores, exercendo pressão positiva para a conservação florestal.
\end{abstract}

Palavras-chave: psicologia ambiental; intenção; atitudes; conservação (comportamento ecológico).

\begin{abstract}
Behavioral intention of farmers from Western Santa Catarina toward conserving native forests . Reconciling the conservation of native forests and agricultural production on rural properties is a complex task that demands systemic and multidisciplinary approaches that include, in addition to the biological aspects of the resources, other socioeconomic, cultural and even psychological aspects. In order to identify and compare the behavioral intention of farmers in the conservation and management of native forests in their rural properties in western Santa Catarina, in this study we applied the Theory of Planned Behavior. We found that the Behavioral Intention of farmers of different production systems, as well as farmers with and without dependence on forest resources native to compose incomes, differ. Differences between groups of farmers regarding the results related to Attitude and Perceived Behavioral Control were consistently associated with socioeconomic and environmental aspects. Results of Subjective Norms indicate that the family is the main reference for farmers, exerting positive pressure for forest conservation.
\end{abstract}

Keywords: environmental psychology; intention; attitudes; conservation (ecological behavior).

\section{Resumen}

La intención que motiva el comportamiento de los agricultores del Oeste de Santa Catarina para conservar los bosques nativos. Conciliar la conservación de los bosques nativos y la producción agrícola en propiedades rurales es una tarea compleja, que demanda enfoques sistémicos y multidisciplinarios, los cuales incluyen, no sólo los aspectos biológicos de los recursos, sino también aspectos de naturaleza socioeconómica, cultural e inclusive, psicológica. En este estudio se buscó identificar y comparar la intención que motiva a los agricultores de la región del oeste de Santa Catarina para que conserven e manejen bosques nativos en sus propiedades rurales, y para tal se utilizó la Teoría del Comportamiento Planificado. Fue constatado que la Intención Comportamental es diferente entre agricultores de sistemas de producción distintos y entre los agricultores que dependan o no de los recursos forestales nativos para constituir sus ingresos. Las diferencias entre los grupos de agricultores con relación a los resultados de Actitud y de Percepción del Control de Comportamiento estaban asociadas consistentemente a aspectos socioeconómicos y ambientales. Los resultados de las Normas Subjetivas indican que la familia es la principal referencia de los agricultores y ésta ejerce una presión positiva en la conservación de los bosques.

Palabras clave: psicologia ambiental; intencion; actitudes; conservacion (conducta ecologica). 
A demanda pela conservação de ecossistemas florestais naturais é crescente, especialmente em países tropicais, em decorrência da elevada redução de habitats e de biodiversidade e da necessidade de redução da emissão de gases de efeito estufa por desmatamentos (Brasil-MCTI, 2010). Da mesma forma se encontra a demanda pela produção agropecuária, visto que estimativas recentes indicam a necessidade de aumento da produção de alimentos no mundo em $60 \%$ até 2050 , a partir do aumento de terras cultivadas, em locais propícios, e da produtividade dos cultivos (OECD/FAO, 2012). Conciliar esses dois objetivos de uso e cobertura da terra é um desafio às sociedades contemporâneas.

No Brasil, diversos trabalhos constataram o descumprimento das regras estabelecidas para a conservação de florestas nativas em imóveis rurais, em especial, a conservação de Áreas de Preservação Permanente definidas no antigo Código Florestal (Lei Federal n ${ }^{\circ}$ 4.771, de 15 de setembro de 1965) (Nascimento, Paulo, Carlos, \& Elias, 2005; Oliveira et al, 2008; Sparovek, Berndes, Klug, \& Barretto, 2010). De forma semelhante, em Santa Catarina verificou-se que limitações ao uso direto de recursos florestais nativos incomodam os agricultores e estes frequentemente descumprem e manifestam discordância em relação à preservação de vegetação nativa em seus imóveis rurais, conforme prevê a legislação vigente, em especial o Novo Código Florestal (Lei Federal 12.651, de 25 de maio de 2012) (Alarcon et al., 2010; Dalmora, 2004; Siminski, 2009). No entanto, ainda não são bem conhecidos os fatores que estão por trás do descumprimento dessas regras.

O desafio que se delineia é complexo e por isso demanda abordagens sistêmicas, como a proposta por Ostrom (2007) para sistemas sócio-ecológicos, na qual o foco central é analisar que variáveis de domínio biofísico e social afetam o comportamento humano e quais os resultados dessas interações em recursos de interesse.

Considerando o exposto, buscou-se neste estudo identificar a intenção comportamental de agricultores residentes na região Oeste de Santa Catarina, em relação à conservação e manejo de florestas nativas em seus imóveis rurais utilizando-se a Teoria do Comportamento Planejado (Ajzen, 1985). Para identificar a relação de variáveis sócio-econômicas com a intenção comportamental dos agricultores foram adotados como critérios de amostragem dos entrevistados variáveis indicadas em estudos anteriores como de possível influência na conservação florestal.

A Teoria do Comportamento Planejado tenta explanar o comportamento humano a partir de um modelo limitado a poucos componentes baseados em crenças pessoais, que são alimentadas por informações, boatos, experiências e conhecimentos (Beedell \& Rehman, 2000). A Teoria do Comportamento Planejado, como proposta por Ajzen (1985), possui uma construção formada por três constructos de crença pessoal sintetizados na expressão abaixo:

$$
\begin{aligned}
B \sim \mathrm{BI} & =\gamma_{1} \sum \mathrm{bs}_{i} \mathrm{oe}_{i}+\gamma_{2} \sum \mathrm{nb}_{j} \mathrm{mc}_{j}+\gamma_{3} \sum \mathrm{cb}_{k} \mathrm{pb}_{k} \\
& =\gamma_{1} \text { Aact }+\gamma_{2} \mathrm{SN}+\gamma_{3} \mathrm{PBC},
\end{aligned}
$$

\author{
Em que, \\ B - Comportamento ou ação \\ BI - Intenção Comportamental \\ Aact - Atitude \\ SN - Normas Subjetivas \\ PBC - Controle Comportamental Percebido \\ bs - força da crença \\ oe - avaliação do resultado \\ $\mathrm{nb}$ - crenças normativas \\ mc - motivação para concordar \\ $\mathrm{cb}$ - crença no controle \\ $\mathrm{pb}$ - poder do controle
}

Segundo o modelo proposto por Ajzen (1985) a Atitude (Aact) se refere à avaliação positiva ou negativa em relação aos resultados decorrentes de um comportamento e pode ser avaliada através da "força da crença" (bs), ou seja, da crença pessoal sobre a probabilidade de um comportamento específico levar a um resultado específico e da "avaliação do resultado" (oe), ou seja, da avaliação pessoal de quão bom ou ruim pode ser um resultado específico de um comportamento. As Normas Subjetivas (SN) se referem à percepção pessoal das pressões sociais existentes para ela executar ou não um comportamento e podem ser avaliadas através das "crenças normativas", ou seja, das crenças pessoais a respeito do que as suas principais referências sociais/afetivas pensam sobre ela exercer ou não um comportamento e através da "motivação para concordar" (mc), ou seja, da avaliação pessoal de quanto se quer satisfazer as principais referências sociais/afetivas (Ajzen, 1985). O Controle Comportamental Percebido (PBC) se refere aos fatores de constrangimento ou encorajamento para se efetuar um comportamento, em condições em que a ação de uma pessoa depende pouco do controle de sua vontade própria. O PBC pode ser avaliado através das "crenças no controle" (cb), ou seja, crenças relativas à probabilidade de determinado fator afetar o comportamento e através do "poder do controle" (pb), ou seja, da avaliação pessoal do poder de determinado fator de controle afetar a execução de determinado comportamento (Ajzen, 1985).

Pesquisa realizada na Alemanha, na região da Floresta Negra, analisou, por meio da Teoria do Comportamento Planejado, como proprietários de florestas avaliavam e implementavam práticas florestais (Bieling, 2004). Verificou-se que os entrevistados acreditavam que podiam contribuir pouco com as condições fitossanitárias, estruturais e de diversidade de suas florestas e que as tomadas de decisões ocorriam somente após a discussão com os familiares e amigos, apesar de considerarem a assistência técnica disponível de boa qualidade (Bieling, 2004). Uma outra pesquisa, na Austrália, utilizando a mesma abordagem, verificou que tanto agricultores interessados em manejar a vegetação de margens de rios, como os não interessados, não diferiam em relação à crença de que os custos financeiros para tal eram uma barreira (Fielding, Deborah, Barbara, Prashant, \& Michael, 2005). 


\section{Métodos}

\section{Área de estudo}

A área de estudo compreende a área do Corredor Ecológico Chapecó, criado pelo Decreto Estadual n ${ }^{\circ}$ 2.957/2010, e localizado na região Oeste do estado de Santa Catarina, no sul do Brasil. Segundo o Sistema Nacional de Unidades de Conservação (Lei Federal n 9.985, de 18 de julho de 2000), os corredores ecológicos são "porções de ecossistemas naturais ou seminaturais, ligando unidades de conservação, que possibilitam entre elas o fluxo de genes e o movimento da biota, facilitando a dispersão de espécies e a recolonização de áreas degradadas, bem como a manutenção de populações que demandam para sua sobrevivência áreas com extensão maior do que aquela das unidades individuais".

O Corredor Ecológico Chapecó possui área de 5.170,47 $\mathrm{Km}^{2}$, compreende a Sub-Bacia do Rio Chapecó e abrange 23 municípios. Esse Corredor é administrado pela Fundação do Meio Ambiente do Estado de Santa Catarina (FATMA) e sua proposta de gestão se baseia em mecanismos econômicos para a valorização dos remanescentes de vegetação natural, não impõe restrições legais adicionais à legislação ambiental vigente, porém pressupõe o seu cumprimento e busca estimulá-lo.

\section{Amostragem}

Foi considerada como unidade amostral a "unidade de produção agrícola" (UPA), que se refere ao conjunto de meios de produção (terra, trabalho e capital) combinados entre si para assegurar uma produção vegetal e/ou animal, submetidos a uma gestão única, de uma ou mais pessoas (Lima, Santos, Muller, Basso, \& Neumann, 2001). Para cada UPA amostrada foi entrevistado o agricultor responsável, sendo preferencialmente do sexo masculino, como forma de padronização da amostra.

Figura 1. Quadro de critérios para Inclusão de Amostras de Unidades de Produção Agrícolas (Upas) no Estudo, Localizadas no Corredor Ecológico Chapecó - SC, Brasil.

Variável

Sistema de produção agropecuário ${ }^{1}$

Sucessão familiar e estágio da vida

Nível de dependência por recursos florestais nativos
$\S$ Agricultura Familiar de Assentamentos

$\S$ Agricultura Familiar Tradicional

$\S$ Agricultura Patronal de Grãos

$\S$ Silvicultura

$\S$ Agricultores sem sucessores na unidade de produção agrícola e em idade inativa ${ }^{2}$ $\S$ Agricultores com sucessores na unidade de produção agrícola ou em idade ativa ${ }^{2}$

$\S$ Dependência para compor renda

$\S$ Dependência para subsistência apenas ou nenhum tipo de dependência

'Definidos a partir do relatório “Plano de Gestão do Corredor Ecológico Chapecó e Timbó” (FATMA - PRAPEM - Microbacias 2, execução Socioambiental Consultores Associados, 2009)

${ }^{2}$ Considerou-se neste trabalho como limite entre idade ativa e inativa 55 anos para homens e mulheres, por ser um valor próximo da idade mínima para aposentadoria por idade para homens no meio rural, que é de 60 anos.

A amostragem foi Intencional ou por Julgamento (Oliveira, 2001) e os critérios adotados para a escolha das unidades amostrais abrangeram três variáveis e oito níveis, apresentados na Figura 1.

Para a variável "sistema de produção agropecuário" utilizou-se a classificação proposta em trabalho técnico anterior na área do Corredor Chapecó (Fundação do Meio Ambiente - FATMA \& Socioambiental, 2009). Os sistemas Familiares (de Assentamento e Tradicional) foram identificados a partir do conceito de agricultura familiar, definido por Bélières, Bonnal, Bosc, Marzin e Sourisseau. (2013) como uma forma de organização da produção agrícola em que existem ligações orgânicas entre as operações da unidade de produção e a mobilização de mão de obra familiar, excluindo salário permanente, com inclusão do capital produtivo no patrimônio familiar. Neste trabalho o sistema Familiar foi subdividido em "de Assentamentos" e "Tradicional", devido principalmente as distinções relativas ao acesso a terra e o tamanho dos imóveis rurais. O sistema "Agricultura Patronal" foi identificado a partir do conceito de agricultura patronal que, segundo Germer (2002), apresenta características de outros tipos de empresas capitalistas como a produção em grande escala, os capitalistas não trabalham na produção, gestão ou administração feita por especialistas e o trabalho é in- 
teiramente realizado por assalariados. O sistema Silvicultura se caracteriza por um sistema de agricultura predominantemente patronal, em que o principal produto é a madeira, produzida a partir de plantios homogêneos de pinheiros e/ou eucaliptos, com processamento ou não da madeira na unidade amostrada.

Em campo as amostras foram escolhidas a partir de combinações únicas dos níveis das variáveis, procurando amostrar de forma equitativa todas as combinações, como um Delineamento Amostral Fatorial (Pearce, 1983). Foram amostradas 99 unidades de produção agrícolas (UPAs), porém três delas não forneceram informações necessárias para as análises.

\section{Instrumento e coleta de dados}

Foram realizadas entrevistas estruturadas com agricultores responsáveis por unidades de produção agrícolas (UPAs) amostradas na área de estudo, contendo perguntas fechadas para os constructos da Intenção Comportamental - Atitude (3 perguntas), Normas Subjetivas (2 perguntas) e Controle Comportamental Percebido (4 perguntas). Todas as perguntas fechadas utilizaram escalas Likert unipolares, de 5 pontos cada, com escores variando de 1 a 5 , adotadas em outras pesquisas de Comportamento Planejado (Figura 2) (Ajzen, 2002; Matos, 2008; Ramalho, 2006). O roteiro de entrevista conti-

Figura 2. Quadro de Escalas Adotadas em Entrevistas com Agricultores do Corredor Ecológico Chapecó-SC, para os Constructos da Teoria do Comportamento Planejado

\begin{tabular}{|c|c|c|c|}
\hline Constructo & Escala utilizada & Âncoras das escalas & Escores \\
\hline Força da crença & Likert unipolar 5 pontos & $\begin{array}{l}\text { "extremamente importante" } \\
\text { "nada importante" }\end{array}$ & $\begin{array}{l}5 \\
1\end{array}$ \\
\hline Avaliação da crença & Likert unipolar 5 pontos & $\begin{array}{l}\text { "muito bom" } \\
\text { "muito ruim" }\end{array}$ & $\begin{array}{l}5 \\
1\end{array}$ \\
\hline Crença normativa & Likert unipolar 5 pontos & $\begin{array}{l}\text { "deveria muito" } \\
\text { "não deveria" }\end{array}$ & $\begin{array}{l}5 \\
1\end{array}$ \\
\hline Motivação a concordar & Likert unipolar 5 pontos & $\begin{array}{l}\text { "concordo totalmente" } \\
\text { "discordo totalmente" }\end{array}$ & $\begin{array}{l}5 \\
1\end{array}$ \\
\hline Crença no controle & Likert unipolar 5 pontos & $\begin{array}{l}\text { "extremamente importante" } \\
\text { "nada importante" }\end{array}$ & $\begin{array}{l}5 \\
1\end{array}$ \\
\hline Poder do controle & Likert unipolar 5 pontos & $\begin{array}{l}\text { "muito fácil" } \\
\text { "muito difícil" }\end{array}$ & $\begin{array}{l}5 \\
1\end{array}$ \\
\hline
\end{tabular}

Fonte: dados da pesquisa

\section{Resultados e discussão}

nha também questões sobre a caracterização sócio-econômica e do sistema de produção do agricultor e de sua UPA. O roteiro estruturado utilizado foi testado a partir das três primeiras entrevistas e algumas alterações foram feitas. As entrevistas foram realizadas nos meses de junho de 2011 e maio de 2012.

\section{Análise dos dados}

Foi feita análise de Normalidade Kolmogorov-Smirnov dos escores dos constructos que formam a Atitude, as Normas Subjetivas e o Controle Comportamental Percebido no software Bioestat 5.0 (Ayres, Ayres Jr., Ayres, \& Santos, 2003), através da qual verificou-se que os dados não aderiam à distribuição Normal. A análise desses constructos foi feita a partir de Estatística Descritiva (mediana e quartis) (Ayres et al, 2003; Beiguelman, 2002) e a comparação dos resultados dos constructos dos agricultores agrupados segundo os critérios adotados na amostragem (Figura 1) foi feita a partir de análise de variância Kruskal-Wallis e teste de separação de médias Dunn, considerando o nível de significância de 5\%, no software Bioestat 5.0 (Ayres et al, 2003).
Caracterização dos agricultores entrevistados e das unidades de produção agrícolas (UPAs)

Os 96 agricultores entrevistados têm, em média, idade de 49 anos $(D P=14)$, variando de 20 a 79 anos, sendo que $33 \%$ deles são aposentados. Dentre os entrevistados, $2 \%$ não tiveram acesso ao ensino formal, 55\% têm Ensino Fundamental incompleto, 12\% têm Ensino Fundamental completo, 3\% têm Ensino Médio incompleto, 18\% têm Ensino Médio completo, $2 \%$ têm Ensino Superior incompleto e $8 \%$ têm Ensino Superior completo.

\section{Comparação da intenção comportamental entre sistemas de produção}

Os resultados dos constructos "Atitude", "força da crença" e "avaliação da crença" para os agricultores agrupados nos sistemas de produção "Familiar de assentamento", "Familiar Tradicional", "Patronal Grãos" e "Silvicultura" são apresentados na Tabela 1. Nessa tabela são apresentados os valores das medianas (em negrito) e dos quartis (entre parênteses) dos escores relativos às escalas Likert utilizadas. Os valores apresentados para a Atitude se referem ao produto de multiplicação de fatores, conforme a expressão proposta por Ajzen (1985). 
Tabela 1. Escores de Atitude, força da crença e avaliação da crença de agricultores do Corredor Ecológico Chapecó, Santa Catarina, agrupados por sistemas de produção, sobre os resultados/conseqüências da conservação de florestas nativas em seus imóveis rurais.

\begin{tabular}{|c|c|c|c|c|c|c|c|c|c|c|c|c|}
\hline & \multicolumn{4}{|c|}{$\begin{array}{c}\text { Escores de força da crença } \\
\text { (mediana e quartis) }\end{array}$} & \multicolumn{4}{|c|}{$\begin{array}{l}\text { Escores de avaliação da crença } \\
\text { (mediana e quartis) }\end{array}$} & \multicolumn{4}{|c|}{$\begin{array}{l}\text { Escores da Atitude } \\
\text { (mediana e quartis) }\end{array}$} \\
\hline & $\begin{array}{l}\text { Fam. } \\
\text { Assent } \\
(\mathrm{n}=25)\end{array}$ & $\begin{array}{l}\text { Fam. } \\
\text { Trad. } \\
(\mathrm{n}=40)\end{array}$ & $\begin{array}{c}\text { Patr. } \\
\text { Grãos } \\
(\mathrm{n}=22)\end{array}$ & $\begin{array}{l}\text { Silv. } \\
(\mathrm{n}=9)\end{array}$ & $\begin{array}{l}\text { Fam. } \\
\text { Assent } \\
(\mathrm{n}=25)\end{array}$ & $\begin{array}{l}\text { Fam. } \\
\text { Trad. } \\
(\mathrm{n}=40)\end{array}$ & $\begin{array}{l}\text { Patr. } \\
\text { Grãos } \\
(\mathrm{n}=22)\end{array}$ & $\begin{array}{l}\text { Silv. } \\
(\mathrm{n}=9)\end{array}$ & $\begin{array}{c}\text { Fam. } \\
\text { Assent } \\
(\mathrm{n}=25)\end{array}$ & $\begin{array}{l}\text { Fam. } \\
\text { Trad. } \\
(\mathrm{n}=40)\end{array}$ & $\begin{array}{l}\text { Patr. } \\
\text { Grãos } \\
(\mathrm{n}=22)\end{array}$ & $\begin{array}{l}\text { Silv. } \\
(\mathrm{n}=9)\end{array}$ \\
\hline & \multicolumn{12}{|c|}{ Crenças Positivas } \\
\hline $\begin{array}{l}\text { Melhoria da qualidade/ } \\
\text { quantidade de água }\end{array}$ & $\begin{array}{c}\mathbf{4}^{\mathbf{a}} \\
(2 / 5)\end{array}$ & $\begin{array}{c}\mathbf{4}^{\mathbf{a}} \\
(1 / 5)\end{array}$ & $\begin{array}{c}\mathbf{4}^{\mathbf{a}} \\
(1 / 5)\end{array}$ & $\begin{array}{c}\mathbf{1}^{\mathbf{b}} \\
(1 / 5)\end{array}$ & $\begin{array}{c}\mathbf{5}^{\mathbf{a}} \\
(2 / 5)\end{array}$ & $\begin{array}{c}\mathbf{4}^{\mathbf{a}} \\
(3 / 5)\end{array}$ & $\begin{array}{c}\mathbf{4}^{\mathbf{a}} \\
(1 / 5)\end{array}$ & $\begin{array}{c}\mathbf{4}^{\mathbf{b}} \\
(3 / 5)\end{array}$ & $\begin{array}{c}\mathbf{2 0}^{\mathbf{a}} \\
(9 / 25)\end{array}$ & $\begin{array}{c}\mathbf{1 6}^{\mathbf{a}} \\
(3 / 25)\end{array}$ & $\begin{array}{c}\mathbf{1 6}^{\mathbf{a}} \\
(3 / 25)\end{array}$ & $\begin{array}{c}\mathbf{5}^{\mathbf{b}} \\
(3 / 20)\end{array}$ \\
\hline Melhoria ambiental geral & $\begin{array}{c}\mathbf{4} \\
(1 / 5)\end{array}$ & $\begin{array}{c}\mathbf{4} \\
(1 / 5)\end{array}$ & $\begin{array}{c}\mathbf{4} \\
(1 / 5)\end{array}$ & $\begin{array}{c}3 \\
(1 / 4)\end{array}$ & $\begin{array}{c}\mathbf{5} \\
(2 / 5)\end{array}$ & $\begin{array}{c}4 \\
(3 / 5)\end{array}$ & $\begin{array}{c}\mathbf{4} \\
(1 / 5)\end{array}$ & $\begin{array}{c}\mathbf{4} \\
(3 / 5)\end{array}$ & $\begin{array}{c}\mathbf{1 6} \\
(4 / 25)\end{array}$ & $\begin{array}{c}\mathbf{1 6} \\
(4 / 25)\end{array}$ & $\begin{array}{c}\mathbf{1 5} \\
(2 / 25)\end{array}$ & $\begin{array}{c}\mathbf{9} \\
(3 / 20)\end{array}$ \\
\hline $\begin{array}{c}\text { Disponibilidade } \\
\text { de recursos para uso }\end{array}$ & $\begin{array}{c}\mathbf{4}^{\mathbf{a}} \\
(1 / 4)\end{array}$ & $\begin{array}{c}3^{\mathbf{a}} \\
(1 / 4)\end{array}$ & $\begin{array}{c}\mathbf{1}^{\mathbf{b}} \\
(1 / 3)\end{array}$ & $\begin{array}{c}\mathbf{1}^{\mathbf{b}} \\
(1 / 3)\end{array}$ & $\begin{array}{c}\mathbf{5} \\
(2 / 5)\end{array}$ & $\begin{array}{c}4 \\
(3 / 5)\end{array}$ & $\begin{array}{c}\mathbf{4} \\
(1 / 5)\end{array}$ & $\begin{array}{c}\mathbf{4} \\
(3 / 5)\end{array}$ & $\begin{array}{c}\mathbf{1 6}^{\mathbf{a}} \\
(4 / 20)\end{array}$ & $\begin{array}{c}\mathbf{1 2}^{\mathbf{a}} \\
(4 / 20)\end{array}$ & $\begin{array}{c}\mathbf{4}^{\mathbf{b}} \\
(1 / 15)\end{array}$ & $\begin{array}{c}\mathbf{4}^{\mathbf{b}} \\
(3 / 9)\end{array}$ \\
\hline $\begin{array}{l}\text { Disponibilidade de } \\
\text { locais para passeio }\end{array}$ & $\begin{array}{c}3 \\
(1 / 5)\end{array}$ & $\begin{array}{c}3 \\
(1 / 5)\end{array}$ & $\begin{array}{c}3 \\
(1 / 5)\end{array}$ & $\begin{array}{c}\mathbf{1} \\
(1 / 4)\end{array}$ & $\begin{array}{c}\mathbf{5} \\
(2 / 5)\end{array}$ & $\begin{array}{c}\mathbf{4} \\
(3 / 5)\end{array}$ & $\begin{array}{c}\mathbf{4} \\
(1 / 5)\end{array}$ & $\begin{array}{c}\mathbf{4} \\
(3 / 5)\end{array}$ & $\begin{array}{c}9 \\
(4 / 25)\end{array}$ & $\begin{array}{c}12 \\
(3 / 20)\end{array}$ & $\begin{array}{c}\mathbf{8 , 5} \\
(2 / 25)\end{array}$ & $\begin{array}{c}\mathbf{4} \\
(3 / 16)\end{array}$ \\
\hline Chance de receber PSA & $\begin{array}{c}\mathbf{1} \\
(1 / 4)\end{array}$ & $\begin{array}{c}\mathbf{1} \\
(1 / 5)\end{array}$ & $\begin{array}{c}\mathbf{3} \\
(1 / 5)\end{array}$ & $\begin{array}{c}\mathbf{1} \\
(1 / 4)\end{array}$ & $\begin{array}{c}\mathbf{5} \\
(2 / 5)\end{array}$ & $\begin{array}{c}\mathbf{4} \\
(3 / 5)\end{array}$ & $\begin{array}{c}\mathbf{4} \\
(1 / 5)\end{array}$ & $\begin{array}{c}\mathbf{4} \\
(3 / 5)\end{array}$ & $\begin{array}{c}\mathbf{5} \\
(2 / 20)\end{array}$ & $\begin{array}{c}\mathbf{5} \\
(3 / 25)\end{array}$ & $\begin{array}{c}\mathbf{5 , 5} \\
(3 / 20)\end{array}$ & $\begin{array}{c}\mathbf{4} \\
(3 / 16)\end{array}$ \\
\hline $\begin{array}{l}\text { Disponibilidade de } \\
\text { recursos para venda }\end{array}$ & $\begin{array}{c}\mathbf{1} \\
(1 / 4)\end{array}$ & $\begin{array}{c}\mathbf{1} \\
(1 / 5)\end{array}$ & $\begin{array}{c}\mathbf{1} \\
(1 / 3)\end{array}$ & $\begin{array}{c}\mathbf{1} \\
(1 / 4)\end{array}$ & $\begin{array}{c}\mathbf{5} \\
(2 / 5)\end{array}$ & $\begin{array}{c}\mathbf{4} \\
(3 / 5)\end{array}$ & $\begin{array}{c}\mathbf{4} \\
(1 / 5)\end{array}$ & $\begin{array}{c}\mathbf{4} \\
(3 / 5)\end{array}$ & $\begin{array}{c}\mathbf{5}^{\mathbf{a}} \\
(2 / 20)\end{array}$ & $\begin{array}{c}\mathbf{4}^{\mathbf{b}} \\
(3 / 25)\end{array}$ & $\begin{array}{c}\mathbf{4}^{\mathbf{b}} \\
(1 / 15)\end{array}$ & $\begin{array}{c}\mathbf{4}^{\text {ab }} \\
(3 / 16)\end{array}$ \\
\hline \multirow[t]{2}{*}{ Local para gado se abrigar } & $\begin{array}{c}3 \\
(1 / 4)\end{array}$ & $\begin{array}{c}3 \\
(1 / 5)\end{array}$ & $\begin{array}{c}\mathbf{1} \\
(1 / 5)\end{array}$ & $\begin{array}{c}\mathbf{1} \\
(1 / 4)\end{array}$ & $\begin{array}{c}\mathbf{5} \\
(2 / 5)\end{array}$ & $\begin{array}{c}\mathbf{4} \\
(3 / 5)\end{array}$ & $\begin{array}{c}\mathbf{4} \\
(1 / 5)\end{array}$ & $\begin{array}{c}\mathbf{4} \\
(3 / 5)\end{array}$ & $\begin{array}{c}\mathbf{1 0}^{\mathbf{a}} \\
(4 / 20)\end{array}$ & $\begin{array}{c}\mathbf{1 2}^{\mathbf{a}} \\
(3 / 25)\end{array}$ & $\begin{array}{c}\mathbf{5}^{\mathbf{a b}} \\
(2 / 20)\end{array}$ & $\begin{array}{c}\mathbf{4}^{\mathbf{b}} \\
(3 / 12)\end{array}$ \\
\hline & \multicolumn{12}{|c|}{ Crença Negativa } \\
\hline $\begin{array}{c}\text { Redução de área } \\
\text { para agropecuária }\end{array}$ & $\begin{array}{c}\mathbf{1} \\
(1 / 5)\end{array}$ & $\begin{array}{c}\mathbf{1} \\
(1 / 4)\end{array}$ & $\begin{array}{c}\mathbf{1} \\
(1 / 4)\end{array}$ & $\begin{array}{c}\mathbf{2} \\
(1 / 5)\end{array}$ & $\begin{array}{c}\mathbf{5} \\
(2 / 5)\end{array}$ & $\begin{array}{c}\mathbf{4} \\
(3 / 5)\end{array}$ & $\begin{array}{c}\mathbf{4} \\
(1 / 5)\end{array}$ & $\begin{array}{c}\mathbf{4} \\
(3 / 5)\end{array}$ & $\begin{array}{c}\mathbf{5} \\
(3 / 20)\end{array}$ & $\begin{array}{c}\mathbf{5} \\
(3 / 16)\end{array}$ & $\begin{array}{c}\mathbf{5} \\
(1 / 20)\end{array}$ & $\begin{array}{c}6 \\
(3 / 20)\end{array}$ \\
\hline
\end{tabular}

Nota. Sistemas de produção: Fam. Assent. = Familiar de Assentamentos; Fam. Trad. = Familiar tradicional; Patr. Grãos = Patronal Grãos e Silv. = Silvicultura. PSA = pagamento por serviços ambientais.

${ }^{a, b}$ Diferenças significativas, considerando o nível de significância de 5\%, entre escores dos sistemas de produção (entre itens da linha), para os constructos 'força da crença', 'avaliação da crença' e 'Atitude'.

Para o constructo "Atitude", que reflete a avaliação positiva ou negativa dos agricultores em relação aos resultados da conservação de florestas em seus imóveis, verificou-se diferenças significativas entre os sistemas de produção para as seguintes crenças: "melhoria da qualidade/quantidade de água" com escores mais baixos para o sistema de produção Silvicultura em relação aos demais sistemas; "disponibilidade de recursos para uso" que apresentou escores mais elevados para os sistemas "Familiares" (de Assentamentos e Tradicional) em relação aos demais sistemas; "disponibilidade de recursos para a venda" que apresentou escores mais elevados para o sistema "Familiar de assentamento", sem, no entanto, diferir significativamente do sistema "Silvicultura"; e "local para o gado se abrigar" com escores mais elevados para os sistemas "Familiares" em relação aos demais sistemas, sem apresentar, no entanto, diferença significativa entre o sistema "Familiar tradicional" e o "Patronal grãos".
Para o contructo "força da crença", que contribui para a formação da "Atitude", foi encontrada diferença significativa para a "melhoria da qualidade/quantidade de água", que obteve escores mais baixos para o sistema de produção "Silvicultura" em relação aos demais sistemas, assim como para a "disponibilidade de recursos para uso" que obteve escores mais elevados para os sistemas "Familiares" em relação aos demais sistemas.

Já para a "avaliação da crença", segundo constructo que contribui para a formação da "Atitude", os escores foram obtidos de forma generalizada, ou seja, foi solicitado aos entrevistados uma avaliação global da conservação das florestas em seus imóveis e não uma avaliação por cada crença em resultados específicos. Para esse constructo foram encontrados escores elevados para todos os sistemas de produção, ou seja, os entrevistados consideram que os resultados da conservação de florestas são positivos, porém os escores do sistema de produção Silvicultura foram significativamen- 
te mais baixos que os dos demais sistemas. Pesquisas anteriores já demonstraram que existe uma percepção positiva dos agricultores em relação à conservação de florestas nativas, relacionadas à beleza, aos animais, à água, ao ar puro, ao lazer, mas que percepções negativas também começam a despontar principalmente associadas à legislação ambiental (Alarcon et al., 2010; Siminski, 2009).

Uma possível explicação para os baixos escores encontrados para o sistema de produção "Silvicultura" em relação à crença no resultado "melhoria da qualidade/quantidade de água" pode ser menor dependência desse sistema por águas superficiais, já que plantas lenhosas geralmente não sofrem muito com escassez de água. Por outro lado, os demais sistemas de produção apresentaram escores elevados para esse resultado porque valorizam esse benefício percebido das florestas possivelmente em decorrência das severas estiagens que vêm ocorrendo na última década na região Oeste de Santa Catarina, principalmente durante a estação de verão, com perdas significativas na produção de grãos.

Os escores mais elevados dos sistemas de produção Familiares em relação ao resultado_"disponibilidade de recursos para uso" estão relacionados com a dependência desses agricultores por recursos florestais nativos em seu cotidiano. Nas unidades de produção familiares da região Sul do Brasil persiste o autoconsumo de espécies florestais nativas para obtenção de energia (lenha), para construção de residências e outras benfeitorias, uso alimentar de frutas nativas e uso medicinal, apesar da redução dos usos madeireiros, a partir da década de 1990, pelo aumento das restrições legais no Bioma Mata Atlântica (Reis, 2006; Siminski, 2009).

Também se destacou nos sistemas Familiares a crença no resultado "local para gado se abrigar" o que é reflexo da grande importância que a produção de leite tem para os agricultores familiares da região Oeste de Santa Catarina. Atualmente essa é uma atividade âncora na composição da renda da agricultura familiar na região, substituindo o papel da suinocultura que passa por um processo de forte concentração (Ferrari, Mello, Testa, \& Silvestro, 2005).

Para os resultados dos constructos das Normas Subjetivas verificou-se que a grande maioria dos agricultores entrevistados (93 agricultores) citou como referência a "família", então, as análises foram feitas exclusivamente para essa referência. Foram encontrados escores elevados para as "crenças normativas", para a "motivação em concordar" e para as "Normas Subjetivas", que não apresentaram diferenças significativas entre os sistemas de produção. Esses resultados indicam que existe forte aceitação da "família" em relação à conservação de florestas e os agricultores estão dispostos em agir conforme essa referência social. De forma semelhante, em trabalho de Bieling (2004), que utilizou a Teoria do Comportamento Planejado entre proprietários de florestas na Alemanha, verificou-se que apesar de $72 \%$ dos entrevistados terem acesso à assistência florestal pública e a considerarem de boa qualidade, a principal referência para as tomadas de decisões sobre o manejo florestal continuava a ser a família, mas também os amigos e vizinhos, com quem as novas informações eram discutidas.

Os resultados dos constructos "Controle Comportamental Percebido", "crença no controle" e "poder do controle" são apresentados na Tabela 2.
O constructo "Controle Comportamental Percebido" reflete fatores que condicionam um comportamento, de forma positiva ou negativa. Fatores que controlam a conservação de florestas (crenças no controle) e que apresentaram diferenças significativas entre sistemas de produção foram "conservar água" com escores mais baixos para o sistema de produção "Silvicultura" em relação ao sistema "Familiar de assentamento" e "uso dos recursos florestais" com escores mais elevados para os sistemas "Familiares" em relação ao sistema "Patronal grãos". Esses resultados se assemelham aos resultados encontrados para o constructo "Atitude", ou seja, fatores como a água e a disponibilidade de recursos para uso, são resultados mas também condicionam a conservação, tendo maior relevância para alguns sistemas de produção em relação a outros, por razões já discutidas acima. Além desses, o "tamanho da propriedade" foi um fator de controle que apresentou escores mais elevados para o sistema "Familiar de assentamento" em relação ao sistema "Silvicultura", possivelmente pelo reduzido tamanho dos imóveis rurais dos agricultores daquele sistema (média de 16,1 ha), o que os limita com mais intensidade a conservar florestas.

Dentre os resultados do constructo "Controle Comportamental Percebido" destacou-se também o fator de controle "relevo" que apresentou escores mais elevados para o sistema "Familiar Tradicional" em relação ao sistema "Patronal Grãos". Esse resultado está relacionado com o relevo mais acidentado da região onde se encontra o sistema de produção Familiar Tradicional no Corredor Ecológico Chapecó, o que pode limitar o uso do solo para atividades agropecuárias (Fundação do Meio Ambiente - FATMA \& Socioambiental, 2009).

Fatores que podem amenizar o controle e encorajar a conservação e que apresentaram diferenças significativas entre os sistemas de produção para o constructo "crenças no controle" foram: "recuperar com espécies úteis", com escores mais elevados para o sistema "Familiar de assentamentos" em relação ao sistema "Patronal grãos" e "orientação técnica" com escores mais elevados para o sistema "Familiar de assentamento" em relação aos demais sistemas. Além desses fatores, para o constructo "Controle Comportamental Percebido", verificou-se diferenças significativas também para "recursos para investir na recuperação", com escores mais elevados para os sistemas "Familiares" em relação ao sistema "Patronal grãos" e "facilidade/permissão de uso", com escores mais elevados para o sistema "Familiar tradicional" em relação aos sistemas "Patronal grãos" e "Silvicultura". Esses resultados indicam que se essas condições (fatores) estivessem disponíveis, o comportamento direcionado à conservação de florestas seria facilitado, especialmente aos agricultores familiares. Possivelmente ações que viabilizem essas condições serão mais efetivas para conservação de florestas entre agricultores familiares do que para os agricultores dos sistemas Patronal Grãos e Silvicultura.

Para o constructo "poder do controle" foram obtidos escores baixos para todos os sistemas de produção (Tabela 2), indicando que existem dificuldades ou resistência ao aumento de florestas nativas nos imóveis rurais nas condições atuais. Esse constructo foi avaliado de forma geral, sem considerar cada fator de controle individualmente, mas sim restrições gerais para aumentar a área de florestas nativas nos imóveis rurais, considerando todos os fatores de controle em conjunto. No entanto, foram encontrados valores significativamente 
Tabela 2. Escores de Controle Comportamental Percebido, crenças no controle e poder do controle para agricultores do Corredor Ecológico Chapecó, Santa Catarina, agrupados por sistemas de produção, para a conservação de florestas nativas em seus imóveis rurais.

\begin{tabular}{|c|c|c|c|c|c|c|c|c|c|c|c|c|}
\hline & \multicolumn{4}{|c|}{$\begin{array}{l}\text { Escores de crenças no controle } \\
\text { (mediana e quartis) }\end{array}$} & \multicolumn{4}{|c|}{$\begin{array}{l}\text { Escores de poder do controle } \\
\text { (mediana e quartis) }\end{array}$} & \multicolumn{4}{|c|}{$\begin{array}{c}\text { Escores do Controle } \\
\text { Comportamental Percebido }\end{array}$} \\
\hline & $\begin{array}{l}\text { Fam. } \\
\text { Assent. }\end{array}$ & $\begin{array}{l}\text { Fam. } \\
\text { Trad. }\end{array}$ & $\begin{array}{l}\text { Patr. } \\
\text { Grãos }\end{array}$ & Silv. & $\begin{array}{l}\text { Fam. } \\
\text { Assent. }\end{array}$ & $\begin{array}{l}\text { Fam. } \\
\text { Trad. }\end{array}$ & $\begin{array}{l}\text { Patr. } \\
\text { Grãos }\end{array}$ & Silv. & $\begin{array}{l}\text { Fam. } \\
\text { Assent. }\end{array}$ & $\begin{array}{l}\text { Fam. } \\
\text { Trad. }\end{array}$ & $\begin{array}{l}\text { Patr. } \\
\text { Grãos }\end{array}$ & Silv. \\
\hline & \multicolumn{12}{|c|}{ Fatores que controlam a conservação } \\
\hline conservar água & $\begin{array}{c}\mathbf{4}^{\mathbf{a}} \\
(3 / 5)\end{array}$ & $\begin{array}{c}\mathbf{4}^{\text {ab }} \\
(1 / 5)\end{array}$ & $\begin{array}{c}\mathbf{4}^{\text {ab }} \\
(1 / 5)\end{array}$ & $\begin{array}{c}\mathbf{1}^{\mathbf{b}} \\
(1 / 5)\end{array}$ & $\begin{array}{c}\mathbf{2}^{\text {ab }} \\
(1 / 5)\end{array}$ & $\begin{array}{c}\mathbf{2}^{\mathbf{a}} \\
(1 / 5)\end{array}$ & $\begin{array}{c}\mathbf{1}^{\mathbf{b}} \\
(1 / 3)\end{array}$ & $\begin{array}{c}\mathbf{1}^{\text {ab }} \\
(1 / 2)\end{array}$ & $\begin{array}{c}\mathbf{1 0}^{\mathbf{a}} \\
(3 / 20)\end{array}$ & $\begin{array}{c}\mathbf{8}^{\mathbf{a b}} \\
(1 / 25)\end{array}$ & $\begin{array}{l}\mathbf{4 , 5} \mathbf{b c} \\
(1 / 12)\end{array}$ & $\begin{array}{c}\mathbf{2}^{\mathbf{c}} \\
(1 / 8)\end{array}$ \\
\hline gosto pela natureza & $\begin{array}{c}\mathbf{4} \\
(1 / 5)\end{array}$ & $\begin{array}{c}\mathbf{4} \\
(1 / 5)\end{array}$ & $\begin{array}{c}\mathbf{3 , 5} \\
(1 / 5)\end{array}$ & $\begin{array}{c}\mathbf{4} \\
(1 / 5)\end{array}$ & $\begin{array}{c}\mathbf{2} \\
(1 / 5)\end{array}$ & $\begin{array}{c}\mathbf{2} \\
(1 / 5)\end{array}$ & $\begin{array}{c}\mathbf{1} \\
(1 / 3)\end{array}$ & $\begin{array}{c}\mathbf{1} \\
(1 / 2)\end{array}$ & $\begin{array}{c}\mathbf{6} \\
(1 / 25)\end{array}$ & $\begin{array}{c}\mathbf{5 , 5} \\
(1 / 20)\end{array}$ & $\begin{array}{c}\mathbf{4} \\
(1 / 12)\end{array}$ & $\begin{array}{c}\mathbf{4} \\
(1 / 10)\end{array}$ \\
\hline relevo & $\begin{array}{c}\mathbf{4} \\
(1 / 5)\end{array}$ & $\begin{array}{c}\mathbf{4} \\
(1 / 5)\end{array}$ & $\begin{array}{c}\mathbf{1 , 5} \\
(1 / 5)\end{array}$ & $\begin{array}{c}\mathbf{4} \\
(2 / 4)\end{array}$ & $\begin{array}{c}\mathbf{2} \\
(1 / 5)\end{array}$ & $\begin{array}{c}2 \\
(1 / 5)\end{array}$ & $\begin{array}{c}\mathbf{1} \\
(1 / 3)\end{array}$ & $\begin{array}{c}\mathbf{1} \\
(1 / 2)\end{array}$ & $\begin{array}{c}\mathbf{4}^{\mathbf{a b}} \\
(1 / 20)\end{array}$ & $\begin{array}{c}7^{\mathbf{a}} \\
(1 / 20)\end{array}$ & $\begin{array}{c}\mathbf{3}^{\mathbf{b}} \\
(1 / 8)\end{array}$ & $\begin{array}{c}\mathbf{4}^{\mathbf{a b}} \\
(2 / 8)\end{array}$ \\
\hline $\begin{array}{l}\text { cumprir as leis } \\
\text { ambientais }\end{array}$ & $\begin{array}{c}3 \\
(1 / 4)\end{array}$ & $\begin{array}{c}\mathbf{2 , 5} \\
(1 / 5)\end{array}$ & $\begin{array}{c}\mathbf{3} \\
(1 / 5)\end{array}$ & $\begin{array}{c}\mathbf{4} \\
(2 / 5)\end{array}$ & $\begin{array}{c}\mathbf{2} \\
(1 / 5)\end{array}$ & $\begin{array}{c}\mathbf{2} \\
(1 / 5)\end{array}$ & $\begin{array}{c}\mathbf{1} \\
(1 / 3)\end{array}$ & $\begin{array}{c}\mathbf{1} \\
(1 / 2)\end{array}$ & $\begin{array}{c}\mathbf{6} \\
(1 / 16)\end{array}$ & $\begin{array}{c}\mathbf{6} \\
(1 / 16)\end{array}$ & $\begin{array}{c}\mathbf{4} \\
(1 / 12)\end{array}$ & $\begin{array}{c}4 \\
(2 / 10)\end{array}$ \\
\hline $\begin{array}{l}\text { uso dos recursos } \\
\text { florestais }\end{array}$ & $\begin{array}{c}\mathbf{4}^{\mathbf{a}} \\
(1 / 5)\end{array}$ & $\begin{array}{c}\mathbf{3}^{\mathbf{a}} \\
(1 / 5)\end{array}$ & $\begin{array}{c}\mathbf{1}^{\mathbf{b}} \\
(1 / 4)\end{array}$ & $\begin{array}{c}\mathbf{1}^{\text {ab }} \\
(1 / 5)\end{array}$ & $\begin{array}{c}\mathbf{2} \\
(1 / 5)\end{array}$ & $\begin{array}{c}2 \\
(1 / 5)\end{array}$ & $\begin{array}{c}\mathbf{1} \\
(1 / 3)\end{array}$ & $\begin{array}{c}\mathbf{1} \\
(1 / 2)\end{array}$ & $\begin{array}{c}\mathbf{6}^{\mathbf{a}} \\
(2 / 20)\end{array}$ & $\begin{array}{c}\mathbf{6}^{\mathbf{a}} \\
(1 / 25)\end{array}$ & $\begin{array}{c}\mathbf{2}^{\mathbf{b}} \\
(1 / 12)\end{array}$ & $\begin{array}{c}\mathbf{2}^{\mathbf{b}} \\
(1 / 10)\end{array}$ \\
\hline $\begin{array}{l}\text { tamanho da } \\
\text { propriedade }\end{array}$ & $\begin{array}{c}\mathbf{2}^{\mathbf{a}} \\
(1 / 4)\end{array}$ & $\mathbf{1}^{\mathrm{ab}}(1 / 4)$ & $\begin{array}{c}\mathbf{1}^{\mathbf{a b}} \\
(1 / 4)\end{array}$ & $\begin{array}{c}\mathbf{1}^{\mathbf{b}} \\
(1 / 1)\end{array}$ & $\begin{array}{c}\mathbf{2} \\
(1 / 5)\end{array}$ & $\begin{array}{c}2 \\
(1 / 5)\end{array}$ & $\begin{array}{c}\mathbf{1} \\
(1 / 3)\end{array}$ & $\begin{array}{c}\mathbf{1} \\
(1 / 2)\end{array}$ & $\begin{array}{c}\mathbf{4}^{\mathbf{a}} \\
(1 / 16)\end{array}$ & $\begin{array}{c}\mathbf{3}^{\mathbf{a b}} \\
(1 / 20)\end{array}$ & $\begin{array}{c}\mathbf{2}^{\mathbf{b c}} \\
(1 / 9)\end{array}$ & $\begin{array}{c}\mathbf{1}^{\mathbf{c}} \\
(1 / 2)\end{array}$ \\
\hline $\begin{array}{c}\text { venda de recursos } \\
\text { florestais }\end{array}$ & $\begin{array}{c}\mathbf{1} \\
(1 / 4)\end{array}$ & $\begin{array}{c}\mathbf{1} \\
(1 / 5)\end{array}$ & $\begin{array}{c}\mathbf{1} \\
(1 / 5)\end{array}$ & $\begin{array}{c}\mathbf{1} \\
(1 / 5)\end{array}$ & $\begin{array}{c}\mathbf{2} \\
(1 / 5)\end{array}$ & $\begin{array}{c}2 \\
(1 / 5)\end{array}$ & $\begin{array}{c}\mathbf{1} \\
(1 / 3)\end{array}$ & $\begin{array}{c}\mathbf{1} \\
(1 / 2)\end{array}$ & $\begin{array}{c}\mathbf{4}^{\mathbf{a}} \\
(1 / 20)\end{array}$ & $\begin{array}{c}\mathbf{2}^{\mathbf{a b}} \\
(1 / 25)\end{array}$ & $\begin{array}{c}\mathbf{1 , 5}^{\mathbf{b}} \\
(1 / 15)\end{array}$ & $\begin{array}{c}\mathbf{2}^{\text {ab }} \\
(1 / 8)\end{array}$ \\
\hline futuro PSA & $\begin{array}{c}\mathbf{1} \\
(1 / 4)\end{array}$ & $\begin{array}{c}\mathbf{1} \\
(1 / 4)\end{array}$ & $\begin{array}{c}\mathbf{1} \\
(1 / 4)\end{array}$ & $\begin{array}{c}\mathbf{1} \\
(1 / 1)\end{array}$ & $\begin{array}{c}\mathbf{2} \\
(1 / 5)\end{array}$ & $\begin{array}{c}2 \\
(1 / 5)\end{array}$ & $\begin{array}{c}\mathbf{1} \\
(1 / 3)\end{array}$ & $\begin{array}{c}\mathbf{1} \\
(1 / 2)\end{array}$ & $\begin{array}{c}2 \\
(1 / 8)\end{array}$ & $\begin{array}{c}2 \\
(1 / 16)\end{array}$ & $\begin{array}{c}\mathbf{1} \\
(1 / 9)\end{array}$ & $\begin{array}{c}\mathbf{1} \\
(1 / 2)\end{array}$ \\
\hline $\begin{array}{l}\text { falta de pessoas para } \\
\text { cultivar a terra }\end{array}$ & $\begin{array}{c}\mathbf{1} \\
(1 / 4)\end{array}$ & $\begin{array}{c}\mathbf{1} \\
(1 / 4)\end{array}$ & $\begin{array}{c}\mathbf{1} \\
(1 / 2)\end{array}$ & $\begin{array}{c}\mathbf{1} \\
(1 / 3)\end{array}$ & $\begin{array}{c}\mathbf{2} \\
(1 / 5)\end{array}$ & $\begin{array}{c}2 \\
(1 / 5)\end{array}$ & $\begin{array}{c}\mathbf{1} \\
(1 / 3)\end{array}$ & $\begin{array}{c}\mathbf{1} \\
(1 / 2)\end{array}$ & $\begin{array}{c}\mathbf{2}^{\mathbf{a b}} \\
(1 / 8)\end{array}$ & $\begin{array}{c}\mathbf{2}^{\mathbf{a}} \\
(1 / 12)\end{array}$ & $\begin{array}{c}\mathbf{1}^{\mathbf{b}} \\
(1 / 3)\end{array}$ & $\begin{array}{c}\mathbf{2}^{\text {ab }} \\
(1 / 3)\end{array}$ \\
\hline & \multicolumn{12}{|c|}{ Fatores que podem amenizar o controle e encorajar a conservação } \\
\hline $\begin{array}{l}\text { pagamento pelas } \\
\text { áreas conservadas }\end{array}$ & $\begin{array}{c}4 \\
(1 / 5)\end{array}$ & $\begin{array}{c}\mathbf{4} \\
(1 / 5)\end{array}$ & $\begin{array}{c}\mathbf{4} \\
(1 / 5)\end{array}$ & $\begin{array}{c}\mathbf{4} \\
(1 / 5)\end{array}$ & $\begin{array}{c}\mathbf{2} \\
(1 / 5)\end{array}$ & $\begin{array}{c}\mathbf{2} \\
(1 / 5)\end{array}$ & $\begin{array}{c}\mathbf{1} \\
(1 / 3)\end{array}$ & $\begin{array}{c}\mathbf{1} \\
(1 / 2)\end{array}$ & $\begin{array}{c}8 \\
(2 / 20)\end{array}$ & $\begin{array}{c}7 \\
(1 / 25)\end{array}$ & $\begin{array}{c}\mathbf{5} \\
(1 / 15)\end{array}$ & $\begin{array}{c}\mathbf{5} \\
(1 / 10)\end{array}$ \\
\hline $\begin{array}{l}\text { recursos para } \\
\text { investir na } \\
\text { recuperação }\end{array}$ & $\begin{array}{c}\mathbf{4} \\
(1 / 5)\end{array}$ & $\begin{array}{c}\mathbf{3} \\
(1 / 5)\end{array}$ & $\begin{array}{c}\mathbf{1} \\
(1 / 5)\end{array}$ & $\begin{array}{c}\mathbf{1} \\
(1 / 5)\end{array}$ & $\begin{array}{c}\mathbf{2} \\
(1 / 5)\end{array}$ & $\begin{array}{c}\mathbf{2} \\
(1 / 5)\end{array}$ & $\begin{array}{c}\mathbf{1} \\
(1 / 3)\end{array}$ & $\begin{array}{c}\mathbf{1} \\
(1 / 2)\end{array}$ & $\begin{array}{c}\mathbf{6}^{\mathbf{a}} \\
(1 / 20)\end{array}$ & $\begin{array}{c}\mathbf{6}^{\mathbf{a b}} \\
(1 / 20)\end{array}$ & $\begin{array}{c}\mathbf{2 , 5}^{\mathbf{c}} \\
(1 / 15)\end{array}$ & $\begin{array}{c}\mathbf{2}^{\mathbf{b c}} \\
(1 / 8)\end{array}$ \\
\hline $\begin{array}{l}\text { facilidade/permissão } \\
\text { de uso dos RFN }\end{array}$ & $\begin{array}{c}3 \\
(1 / 4)\end{array}$ & $\begin{array}{c}\mathbf{4} \\
(1 / 5)\end{array}$ & $\begin{array}{c}3 \\
(1 / 5)\end{array}$ & $\begin{array}{c}\mathbf{1} \\
(1 / 4)\end{array}$ & $\begin{array}{c}\mathbf{2} \\
(1 / 5)\end{array}$ & $\begin{array}{c}\mathbf{2} \\
(1 / 5)\end{array}$ & $\begin{array}{c}\mathbf{1} \\
(1 / 3)\end{array}$ & $\begin{array}{c}\mathbf{1} \\
(1 / 2)\end{array}$ & $\begin{array}{c}\mathbf{4}^{\text {ac }} \\
(1 / 15)\end{array}$ & $\begin{array}{c}\mathbf{7}^{\mathbf{c}} \\
(1 / 25)\end{array}$ & $\begin{array}{c}\mathbf{3 , 5} \mathbf{a b} \\
(1 / 12)\end{array}$ & $\begin{array}{c}\mathbf{2}^{\text {ab }} \\
(1 / 8)\end{array}$ \\
\hline $\begin{array}{l}\text { recuperar com } \\
\text { espécies úteis }\end{array}$ & $\begin{array}{c}\mathbf{4}^{\mathbf{a}} \\
(1 / 4)\end{array}$ & $\begin{array}{c}\mathbf{3}^{\text {ab }} \\
(1 / 5)\end{array}$ & $\begin{array}{c}\mathbf{1}^{\mathbf{b}} \\
(1 / 5)\end{array}$ & $\begin{array}{c}\mathbf{1}^{\text {ab }} \\
(1 / 5)\end{array}$ & $\begin{array}{c}\mathbf{2} \\
(1 / 5)\end{array}$ & $\begin{array}{c}\mathbf{2} \\
(1 / 5)\end{array}$ & $\begin{array}{c}\mathbf{1} \\
(1 / 3)\end{array}$ & $\begin{array}{c}\mathbf{1} \\
(1 / 2)\end{array}$ & $\begin{array}{c}\mathbf{6}^{\mathbf{a}} \\
(1 / 16)\end{array}$ & $\begin{array}{c}\mathbf{6}^{\mathbf{a}} \\
(1 / 16)\end{array}$ & 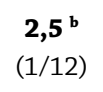 & $\begin{array}{c}\mathbf{2}^{\mathbf{a b}} \\
(1 / 10)\end{array}$ \\
\hline orientação técnica & $\begin{array}{c}\mathbf{4}^{\mathbf{a}} \\
(1 / 5)\end{array}$ & $\begin{array}{c}\mathbf{3}^{\mathbf{b}} \\
(1 / 5)\end{array}$ & $\begin{array}{l}\mathbf{2 , 5} \mathbf{b} \\
(1 / 4)\end{array}$ & $\begin{array}{c}\mathbf{1}^{\mathbf{b}} \\
(1 / 5)\end{array}$ & $\begin{array}{c}\mathbf{2} \\
(1 / 5)\end{array}$ & $\begin{array}{c}\mathbf{2} \\
(1 / 5)\end{array}$ & $\begin{array}{c}\mathbf{1} \\
(1 / 3)\end{array}$ & $\begin{array}{c}\mathbf{1} \\
(1 / 2)\end{array}$ & $\begin{array}{c}\mathbf{6}^{\mathbf{a}} \\
(1 / 16)\end{array}$ & $\begin{array}{c}\mathbf{5 , 5} \mathbf{5}^{\mathbf{a b}} \\
(1 / 25)\end{array}$ & $\begin{array}{c}\mathbf{3}^{\mathbf{b}} \\
(1 / 12)\end{array}$ & $\begin{array}{c}\mathbf{2}^{\mathbf{b}} \\
(1 / 6)\end{array}$ \\
\hline $\begin{array}{l}\text { facilidade/permissão } \\
\text { de venda dos RFN }\end{array}$ & $\begin{array}{c}\mathbf{3} \\
(1 / 5)\end{array}$ & $\begin{array}{c}\mathbf{1} \\
(1 / 5)\end{array}$ & $\begin{array}{c}\mathbf{2 , 5} \\
(1 / 4)\end{array}$ & $\begin{array}{c}\mathbf{3} \\
(1 / 5)\end{array}$ & $\begin{array}{c}\mathbf{2} \\
(1 / 5)\end{array}$ & $\begin{array}{c}2 \\
(1 / 5)\end{array}$ & $\begin{array}{c}\mathbf{1} \\
(1 / 3)\end{array}$ & $\begin{array}{c}\mathbf{1} \\
(1 / 2)\end{array}$ & $\begin{array}{c}\mathbf{4} \\
(1 / 16)\end{array}$ & $\begin{array}{c}\mathbf{4} \\
(1 / 25)\end{array}$ & $\begin{array}{c}\mathbf{3} \\
(1 / 12)\end{array}$ & $\begin{array}{c}\mathbf{5} \\
(1 / 10)\end{array}$ \\
\hline $\begin{array}{l}\text { mão de obra para } \\
\text { recuperação }\end{array}$ & $\begin{array}{c}\mathbf{2} \\
(1 / 4)\end{array}$ & $\begin{array}{c}\mathbf{3} \\
(1 / 5)\end{array}$ & $\begin{array}{c}\mathbf{1} \\
(1 / 5)\end{array}$ & $\begin{array}{c}\mathbf{1} \\
(1 / 4)\end{array}$ & $\begin{array}{c}\mathbf{2} \\
(1 / 5)\end{array}$ & $\begin{array}{c}\mathbf{2} \\
(1 / 5)\end{array}$ & $\begin{array}{c}\mathbf{1} \\
(1 / 3)\end{array}$ & $\begin{array}{c}\mathbf{1} \\
(1 / 2)\end{array}$ & $\begin{array}{c}\mathbf{4} \\
(1 / 12)\end{array}$ & $\begin{array}{c}\mathbf{5} \\
(1 / 16)\end{array}$ & $\begin{array}{c}\mathbf{2 , 5} \\
(1 / 12)\end{array}$ & $\begin{array}{c}\mathbf{2} \\
(1 / 6)\end{array}$ \\
\hline
\end{tabular}

Nota . Sistemas de produção: Fam. Assent. = Familiar de Assentamentos; Fam. Trad. = Familiar tradicional; Patr. Grãos = Patronal Grãos e Silv. = Silvicultura. PSA = pagamento por serviços ambientais. RFN = recursos florestais nativos.

a,b,c Diferenças significativas, considerando o nível de significância de 5\%, entre escores dos sistemas de produção (entre itens da linha), para os constructos 'crenças no controle', 'poder do controle' e 'Controle Comportamental Percebido'. 
mais elevados para o sistema "Familiar Tradicional" em relação ao sistema "Patronal grãos", indicando que para este último grupo a possibilidade de aumento de áreas de florestas em seus imóveis rurais é menor.

Os resultados do somatório total da "Atitude", "Normas Subjetivas" e "Controle Comportamental Percebido" dos agricultores agrupados por sistemas de produção são apresentados na Tabela 3, assim como os valores da "Intenção Comportamental" que reflete o direcionamento global em relação a um comportamento.
Os agricultores dos sistemas de produção Familiares apresentaram maiores escores para Atitude e Controle Comportamental Percebido, o que resultou em diferenças significativas desses sistemas para a Intenção Comportamental, em relação aos demais. Esse resultado representa maior predisposição dos agricultores dos sistemas Familiares em conservar florestas nativas em seus imóveis rurais. Conforme o modelo proposto pela Teoria do Comportamento Planejado, essa maior predisposição seria decorrente da crença desses agricultores em resultados mais

Tabela 3. Escores de Atitude, Normas Subjetivas, Controle Comportamental Percebido e Intenção Comportamental de agricultores do Corredor Ecológico Chapecó, Santa Catarina, agrupados por sistemas de produção.

Escores

(mediana e quartis)

\begin{tabular}{|c|c|c|c|c|}
\hline & & & & \\
\hline & $\begin{array}{l}\text { Familiar de } \\
\text { Assentamento } \\
\quad(n=25)\end{array}$ & $\begin{array}{l}\text { Familiar } \\
\text { Tradicional } \\
(n=40)\end{array}$ & $\begin{array}{l}\text { Patronal Grãos } \\
\quad(n=22)\end{array}$ & $\begin{array}{c}\text { Silvicultura } \\
\quad(n=9)\end{array}$ \\
\hline Atitude & $\begin{array}{c}\mathbf{1 0 0}^{\mathrm{a}} \\
(85 / 115)\end{array}$ & $\begin{array}{l}\mathbf{8 4} 4^{\text {ab }} \\
(71 / 97)\end{array}$ & $\begin{array}{c}\mathbf{6 6}^{\mathbf{b c}} \\
(51 / 93,2)\end{array}$ & $\begin{array}{c}\mathbf{6 4}^{\mathrm{c}} \\
(45 / 68)\end{array}$ \\
\hline Normas Subjetivas & $\begin{array}{c}\mathbf{2 0} \\
(20 / 25)\end{array}$ & $\begin{array}{c}\mathbf{2 0} \\
(20 / 25)\end{array}$ & $\begin{array}{l}\mathbf{2 2 , 5} \\
(20 / 25)\end{array}$ & $\begin{array}{c}\mathbf{2 5} \\
(16 / 25)\end{array}$ \\
\hline $\begin{array}{c}\text { Controle Comportamental } \\
\text { Percebido }\end{array}$ & $\begin{array}{c}\mathbf{9 4}^{\mathrm{a}} \\
(57 / 156)\end{array}$ & $\begin{array}{c}\mathbf{8 0}^{\mathbf{a}} \\
(59 / 137)\end{array}$ & $\begin{array}{c}\mathbf{4 6}^{\mathbf{b}} \\
(36,2 / 74)\end{array}$ & $\begin{array}{c}47^{\mathrm{ab}} \\
(41 / 64)\end{array}$ \\
\hline Intenção Comportamental & $\begin{array}{c}\mathbf{2 1 1}^{\mathbf{a}} \\
(174 / 265)\end{array}$ & $\begin{array}{c}\mathbf{1 9 2 , 5}^{\mathbf{a}} \\
(158 / 240)\end{array}$ & $\begin{array}{c}\mathbf{1 5 4}^{\mathbf{b}} \\
(118,5 / 172)\end{array}$ & $\begin{array}{c}\mathbf{1 1 8}^{\mathbf{b}} \\
(117 / 147)\end{array}$ \\
\hline
\end{tabular}

a,b,c Diferenças significativas, considerando o nível de significância de 5\%, entre escores dos sistemas de produção (entre itens da linha), para os constructos 'Atitude', 'Normas Subjetivas', 'Controle Comportamental Percebido' e 'Intenção Comportamental'.

importantes e mais positivos da conservação, assim como do maior peso de condicionantes (fatores de controle), em relação aos demais sistemas de produção.

A maior predisposição para conservação encontrada nos sistemas Familiares pode ser relacionada com uma característica inerentes à agricultura familiar que é a forte ligação entre a produção e o patrimônio (Bélières et al., 2013), incluindo os recursos naturais dos imóveis rurais, que precisam ser conservados em longo prazo para garantir a transmissão intergeracional.

\section{Comparação da intenção comportamental de agricultores por sucessão familiar e estágio de vida}

Nessa comparação foram encontradas diferenças significativas para os constructos "força da crença" $[\mathrm{H}(1,69)=5,05$; $p=0,02]$ e "Atitude" $[\mathrm{H}(1,69)=4,11 ; p=0,04]$ apenas para o resultado "disponibilidade de recursos para uso", com escores mais elevados para os agricultores "Sem sucessão e em idade inativa" em relação aos "Com sucessão ou em idade ativa".
Para os constructos "Controle Comportamental Percebido" e "crença no controle" foram encontradas diferenças significativas apenas para os fatores "gosto pela nature$z a$ " $[\mathrm{H}(1,69)=4,46 ; p=0,03]$ e "uso dos recursos florestais" $[\mathrm{H}(1,69)=9,99 ; p=0,001]$ com escores mais elevados para os agricultores "Sem sucessão e em fase inativa".

Esses resultados dão indicativo de que o uso direto dos recursos é mais saliente entre agricultores mais velhos, prática que no passado não sofria restrições e era bastante disseminada entre os agricultores de Santa Catarina. A partir da década de 1990, o uso de recursos florestais nativos passou a ter fortes restrições legais, o que pode explicar a falta de expressão dessa prática na atualidade, entre os agricultores mais jovens. A relevância e o conhecimento sobre os recursos naturais em populações humanas são mantidos por meio da prática cotidiana e a aquisição do conhecimento individual é gradual ao longo da vida (Phillips \& Gentry, 1993), fatores que podem explicar as diferenças encontradas.

Além disso, essa relação dos agricultores mais velhos com as florestas pode ter gerado uma relação de afetividade, 
identificada quando ressaltam o "gosto pela natureza" como um fator que motiva a conservação de florestas. Esse tema poderia ser mais aprofundado a partir de estudos de topofilia, que segundo Tuan (1980), é o elo afetivo entre a pessoa e o lugar ou ambiente físico, podendo este não ser a causa direta da topofilia, mas fornecer estímulo sensorial que, ao agir como imagem percebida, dá forma a alegrias e ideais.

\section{Comparação da intenção comportamental de agricultores segundo a dependência por recursos florestais nativos}

A comparação desses agricultores apresentou diferença significativa somente para o resultado "disponibilidade de recursos para a venda" $[\mathrm{H}(1,66)=9,46 ; p=0,002]$ no constructo "Atitude" com escores mais elevados para os agricultores "Dependentes para compor a renda".

Os agricultores "Dependentes para compor a renda" também apresentaram escores significativamente mais elevados para o constructo "crença no controle" para os fatores "gosto pela natureza" $[\mathrm{H}(1,66)=4,44 ; p=0,03]$ e "venda de recursos florestais" $[\mathrm{H}(1,66)=19,62 ; p<0,0001]$ e para esses mesmos dois fatores mas também para "futuro pagamento por serviços ambientais" $[\mathrm{H}(1,66)=4,24 ; p=0,04]$ para o constructo "Controle Comportamental Percebido", quando comparados aos demais agricultores.

Dentre os fatores com potencial para encorajar a conservação, para os agricultores "Dependentes para compor a renda", foram encontradas diferenças significativas e maiores escores, tanto no constructo "crenças no controle" como no constructo "Controle Comportamental Percebido", para os fatores "pagamento pelas áreas conservadas" $[\mathrm{H}(1,66)=7,12$; $p=0,007]$, "orientação técnica" $[\mathrm{H}(1,66)=5,23 ; p=0,02]$ e "facilidade/permissão de venda dos RFN" $[\mathrm{H}(1,66)=9,22 ; p=$ 0,002]. Esses fatores encorajadores possivelmente têm relação direta com a atividade de exploração de recursos florestais nativos que os agricultores "Dependentes para compor a renda" desenvolvem, que se restringe, nesta pesquisa, à exploração de erva-mate. O pagamento por serviços ambientais é uma opção que esses agricultores vislumbram pela possibilidade de obter renda extra das áreas que já conservam para sua exploração florestal. Entende-se por Pagamento por Serviços Ambientais (PSA) aqueles pagamentos condicionais, contratualmente estipulados, para proprietários e usuários locais de recursos naturais, pela adoção de práticas que garantam a conservação e a recuperação de ecossistemas, a partir de beneficiários externos (Wunder, 2005).

A orientação técnica é citada pelos "Dependentes para compor a renda" devido à completa carência em extensão rural direcionada a esse tipo de atividade. Além disso, as restrições legais existentes para a exploração comercial de espécies nativas do Bioma Mata Atlântica (Reis, 2006; Siminski, 2009), possivelmente levou esses agricultores a destacarem o fator de controle "facilidade/permissão de venda dos RFN".

A análise global do modelo apresentou escores significativamente mais elevados para os agricultores "Dependentes para compor a renda" para o "Controle Comportamental Percebido" $[\mathrm{H}(1,66)=4,38 ; p=0,04]$, assim como para a "Intenção Comportamental" $[\mathrm{H}(1,66)=6,42 ; p=0,01]$, demonstrando que agricultores com essa característica estão mais predispostos a conservar florestas nativas em seus imóveis rurais.

\section{Conclusões}

A utilização dos métodos propostos pela Teoria do Comportamento Planejado neste trabalho possibilitou identificar crenças que estão por trás da intenção comportamental de agricultores em conservar e manejar florestas nativas em seus imóveis rurais, trazendo elementos para a discussão sobre o cumprimento ou necessidade de adaptação da legislação ambiental. No entanto, percebe-se que a utilização dos métodos propostos por essa Teoria demanda conhecimento aprofundado sobre os conceitos postulados e implica em considerável dificuldade para formulação de entrevistas.

A associação de fatores sócio-econômicos com os componentes do modelo da Teoria do Comportamento Planejado permitiu identificar crenças distintas entre agricultores de diferentes sistemas de produção agropecuários e de agricultores dependentes ou não de recursos florestais nativos para compor a renda. Agricultores dos sistemas de produção Familiares (de Assentamentos e Tradicional) estão mais predispostos a conservar florestas em seus imóveis porque acreditam em resultados mais importantes e mais positivos da conservação, assim como no maior peso de condicionantes, em relação aos sistemas patronais (Patronal de Grãos e Silvicultura). Esses resultados possivelmente estão associados com as relações patrimonial e de topofilia para com o imóvel rural presentes na agricultura familiar.

Os agricultores dependentes por recursos florestais nativos para compor a renda estão mais predispostos a conservar florestas do que os não dependentes devido, principalmente, a fatores que poderiam encorajar o comportamento de conservação, como o pagamento pelos serviços ambientais, ação que começa a despontar em políticas públicas no país.

A família é a principal referência dos agricultores entrevistados para as decisões relativas ao tema e se mostra favorável à conservação de florestas.

\section{Agradecimentos}

Aos agricultores que participaram voluntariamente da pesquisa e à CAPES pela bolsa de estudo.

\section{Referências}

Ajzen, I. (1985). From intentions to actions: A theory of planned behavior. In J. Kuhi \& J. Beckmann (Orgs.), Action-control: From cognition to behavior (pp. 11-39). Heidelberg: Springer.

Ajzen, I. (2002). Constructing a TpB questionnaire: Conceptual and methodological considerations. Recuperado de http://socgeo.ruhosting.nl/html/files/ spatbeh/tpb.measurement.pdf

Alarcon, G. G., Beltrame, A. V., \& Karam, K. F. (2010). Conflitos de interesse entre pequenos produtores rurais e a conservação de áreas de preservação permanente na Mata Atlântica. Floresta, 40(2), 195-310. doi: 10.5380/rf.v40i2.17825

Ayres, M., Ayres Jr., M., Ayres, D. L., \& Santos, A. S. (2003). BioEstat 3.0. Aplicações estatísticas nas áreas das ciências biológicas e médicas. Belém: Sociedade Civil de Mamirauá. 
Beedell, J., \& Rehman, T. (2000). Using social-psychology models to understand farmers" conservation behaviour: The relationship of verbal and overt verbal responses to attitude objects. Journal of Rural Studies, 16, 117-127. doi:10.1016/S0743-0167(99)00043-1

Beiguelman, B. (2002). Curso prático de bioestatística. Ribeirão Preto: Fundação de Pesquisas Científicas de Ribeirão Preto.

Bélières, J. F., Bonnal, P. H., Bosc, P. -M., Marzin, J., \& Sourisseau, J. -M. (2013). Les agriculteurs familiales du monde: Définitions, contributions e politiques publiques. Montpellier: CIRAD.

Bieling, C. (2004). Non-industrial private-forest owners: Possibilities for increasing adoption of close-to-nature forest management. Europe Journal Forest Resources, 123(4), 293-303. doi: 10.1007/s10342-004-0042-6

Brasil-MCTI (2010). Emissões de gases de efeito estufa no setor uso da terra, mudança no uso da terra e florestas. Relatórios de Referência: Uso da terra e florestas. $2^{\circ}$ Inventário Brasileiro de Emissões e Remoções Antrópicas de Gases de Efeito Estufa. Brasília, DF: MCTI.

Dalmora, E. (2004). O papel da agricultura familiar no processo de conservação da Mata Atlântica em Santa Catarina: modos de apropriação e transformações no sistema de gestão ambiental na década de 1990 (Tese de Doutorado). Universidade Federal de Santa Catarina, Florianópolis. Recuperado de http://repositorio.ufsc.br/xmlui/handle/123456789/87312

Decreto Estadual n ${ }^{\circ}$ 2.957. (2010, 20 de janeiro). Institui o Corredor Ecológico Chapecó na região da Sub-Bacia Hidrográfica do Rio Chapecó.

Ferrari, D. L., Mello, M. A., Testa,V. M., \& Silvestro, M. L. (2005). Agricultores familiares, exclusão e desafios para a inserção econômica na produção de leite em Santa Catarina. Informaçôes Econômicas SP, 35(1), 22-36. Recuperado de http://www.iea.sp.gov.br/out/publicacoes/ieant.php

Fielding, K. S., Deborah, J. T., Barbara, M. M., Prashant, B., \& Michael, A. H. (2005). Explaining landholders" decisions about riparian zone management: The role of behavioural, normative, and control beliefs. Journal of Environmental Management, 77, 12-21. doi: 10.1016/j.jenvman.2005.03.002

Fundação do Meio Ambiente - FATMA, \& Socioambiental Consultores Associados LTDA. (2009). Plano de gestão do corredor ecológico Chapecó. Relatório técnico do projeto planejamento e implementação do corredor ecológico Chapecó. Florianópolis: Socioambiental e FATMA.

Germer, C. M. (2002). A irrelevância prática da agricultura "familiar" para o emprego agrícola. Reforma Agrária, 31(1), 47-62. Recuperado de http:// www.abrareformaagraria.org/sites/default/files/1_jan_abr2002.pdf

Lei Federal no 4.771, de 15 de setembro de 1965. Institui o novo Código Florestal. Recuperado de http://www.planalto.gov.br/ccivil_03/leis/L4771. htm

Lei Federal no 9.985, de 18 de julho de 2000. Regulamenta o art. 225, § $1^{\circ}$, incisos I, II, III, e VII da Constituição Federal, institui o Sistema Nacional de Unidades de Conservação da Natureza e dá outras providências. Recuperado de http://www.planalto.gov.br/ccivil_03/leis/L9985.htm

Lei Federal ${ }^{\circ} 12.651$, de 25 de maio de 2012. Dispõe sobre a proteção da vegetação nativa; altera as Leis nos 6.938, de 31 de agosto de 1981, 9.393, de 19 de dezembro de 1996, e 11.428, de 22 de dezembro de 2006; revoga as Leis nos 4.771, de 15 de setembro de 1965, e 7.754, de 14 de abril de 1989, e a Medida Provisória no 2.166-67, de 24 de agosto de 2001; e dá outras providências. Recuperado de http://www.planalto.gov.br/ ccivil_03/_ato2011-2014/2012/lei/112651.htm

Lima, A. P., Santos, A. C., Muller, A. G., Basso, N., \& Neumann, P. S. (2001). Administração da unidade de produção familiar: modalidades de trabalho com agricultores. Ijuí: UNIJUÍ.

Matos, E. B. (2008). A intenção de uso de preservativo: um estudo de adolescentes comparando gêneros e classes sócias (Dissertação de Mestrado). Universidade Federal de Minas Gerais. Recuperado de http://hdl.handle. net/1843/FACE-7Q3QN8

Nascimento, M. C., Paulo, V. S., Carlos, A. A. S. R., \& Elias, S. (2005). Uso do geoprocessamento na identificação de conflito de uso da terra em áreas de preservação permanente na bacia hidrográfica do rio Alegre, Espírito Santo. Ciência Florestal, 15(2), 207-220. doi: 10.5902/19805098
OECD/FAO (2012). OECD/FAO Agricultural Outlook 2012-2021. OECD Publishing \& FAO. Recuperado de http://dx.doi.org/10.1787/agr_outlook2012-en

Oliveira, T. M. V. (2001). Amostragem não-probabilística: adequação de situações para uso e limitações de amostras por conveniência, julgamento e quotas. Administração on line, 2(3). Recuperado de http://www.fecap.br/ adm_online/art23/tania2.htm

Oliveira, F. S., Soares, V. P., Pezzopane, Gleriani, J. M., Lima, G. S., Silva, E., .. Oliveira, A. M. S. (2008). Identificação de conflito de uso da terra em áreas de preservação permanente no entorno do parque nacional do Caparaó, Estado de Minas Gerais. Revista Árvore, 32(5), 899-908. doi: 10.1590/S0100-67622008000500015

Ostrom, E. (2007). A diagnostic approach for going beyond panaceas. PNAS, 104(39), 15181-15187. doi: 10.1073/pnas.0702288104

Pearce, F. C. (1983). The agricultural field experiment: A statistical examination of theory and practice. Chichester: J. Wiley \& Sons.

Phillips, O., \& Gentry, A. H. (1993). The useful plants of Tambopata, Peru: II. Additional hypothesis testing in quantitative ethnobotany. Economic Botany, 47, 33-43. doi: 10.1007/BF02862204

Ramalho, W. (2006). Modelos de atitude em mercados de produtos novos en trantes: análise com medicamentos genéricos, contribuições teóricas e validação nomológica (Tese de Doutorado). Universidade Federal de Minas Gerais. Recuperado de http://www.bibliotecadigital.ufmg.br/dspace/ bitstream/handle/1843/EMLE-6W7HNY/wanderley_ramalho.pdf?sequence $=1$

Reis, M. S. (2006). Extrativismo no Sul e Sudeste do Brasil: caminhos para a sustentabilidade socioambiental. In R. R. Kubo, J. B. Bassi, G. C. Souza, N. L. Alencar, P. M. Medeiros, \& U. P. Albuquerque (Orgs.), Atualidades em etnobiologia e etnoecologia (Vol. 3, pp. 117-128). NUPEEA/SBEE.

Siminski, A. (2009). A floresta do futuro: conhecimento, valorização e perspectivas de uso das formações florestais secundárias no Estado de Santa Catarina (Tese de Doutorado). Universidade Federal de Santa Catarina. Recuperado de http://repositorio.ufsc.br/xmlui/handle/123456789/92694

Sparovek, G., Berndes, G., Klug, I. L. F., \& Barretto, A. G. O. P. (2010). Brazilian agriculture and environmental legislation: Status and future challenges. Environmental Science \& Technology, 44(16), 6046-6053. doi: 10.1021/ es1007824

Tuan, Y. F. (1980). Topofilia: um estudo da percepção, atitudes e valores do meio ambiente. São Paulo: DIFEL.

Wunder, S. (2005). Payments for environmental services: Some nuts and bolts. CIFOR Occasional Paper No. 42. Jakarta, Indonésia: Center for International Forestry Research. doi: 10.17528/cifor/001760 
Elaine Zuchiwschi, Doutora em Ciências, área de concentração em Recursos Genéticos Vegetais, pela Universidade Federal de Santa Catarina (PPG RGV/UFSC), é Analista técnica em Gestão Ambiental na Fundação do Meio Ambiente do Estado de Santa Catarina (Fundação do Meio Ambiente - FATMA). Endereço para correspondência: Rua Trajano, 81, Centro, Florianópolis-SC, CEP 88010

010. Telefone: (48) 33894464. E-mail: ezuchws@yahoo.com.br

Alfredo Celso Fantini, Doutor em Ciências Florestais pela University of Wisconsin (WISC, Madison, EUA), pós-doutorado pela Australian National University (ANU, Austrália), é Professor adjunto na Universidade Federal de Santa Catarina (UFSC). E-mail afantini@cca.ufsc.br 